\title{
15. Managing trans-boundary crises: leadership challenges for the EU Presidency
}

\author{
Bengt Sundelius
}

\section{Crises without borders}

In the bulk of this book, research findings have been presented on how national leaders have handled the many aspects of the recent international financial collapse and its multiple effects on their societies. Theoretically informed empirical examinations of several political systems have shown the perils of leadership under severe financial conditions. We expect much from our public leaders in the national hot seats.

In this chapter, I heighten the stakes of top-level crisis management even further. Trans-boundary crises such as the financial meltdown in 2008-09 or the likely pandemics of the 2009 influenza season are even more complex than more common disasters that are by and large bounded by space and time. The global financial crisis of 2008-09 as examined in this volume is an early example of a type of fast-paced and vastly diffused development that leaders are likely to experience more frequently in future years.

Trans-boundary phenomena require that multiple actors in distinct jurisdictions, in coherent ways, jointly handle the shared crisis and its often-unexpected aftershocks. The leaders of the G8 and G20 member states were activated in the global financial crisis for this reason. In the European Union, the European Commission and the European Central Bank were very active (see Fletcher, this volume). The French Presidency during the second half of 2008 headed the common crisis-management efforts that involved a number of initiatives, top-level meetings and financial support packages (see Windle, this volume).

In Europe, a multilevel form of crisis management is emerging. Effective crisis coordination must here be fostered across levels, sectors, institutions and sovereign jurisdictions. It would be prudent to strengthen European networks of crisis coordination before events overtake the capacity for effective joint management. This type of preparatory work is well under way and it seems to have been given some priority by current and recent presidencies. The legitimacy of the European Union can be strengthened and the social distance to its citizens can be shortened when the common union capacity to manage crises is put to the test by unexpected trans-boundary phenomena. 
The Presidency of the European Union is responsible for multinational, multilevel, multi-sector and multi-institutional leadership in situations of severe stress for the union, its 27 member states and almost 500 million people. During the second half of 2009, Sweden serves in this capacity. In his program statement of 1 July, the Swedish Prime Minister and EU President, Fredrik Reinfeldt, listed the top-priority issues facing his six-month tenure: finding a durable solution to climate change and overcoming the financial collapse. Reinfeldt concluded the manifesto boldly: 'We must also be prepared to manage the unexpected. Sweden is ready to meet this challenge.' Many observers claim that the test of the performance of an EU President rests on the ability to excel in public leadership in the high-stakes and very visible media setting of dealing with gravely consequential problems that are not yet known. Some presidencies do very well — such as the French term during 2008 - while others fare less well.

This memo is directed to the holders of the EU Presidency. I am convinced that research into crisis management has practical value. Recognising all the limitations of trying to turn research findings into 'how-to' (or more often 'how-not-to') recommendations, this essay draws on the scholarly evidence for reflections and advice to the incumbent EU Presidency. Leaders have to face the challenges, make choices and live with the consequences of their action or inaction. After many years of observation of crisis leadership, I have considerable respect for the difficulties and burdens of exercising authority and upholding credibility in crisis - in particular, when facing trans-boundary phenomena. My normative stand is that I applaud crisis leadership practices that help minimise human and material losses and other societal costs, while also upholding fundamental values of democratic governance, the rule of law and citizen rights. When our academic understanding can in modest ways enhance crisis leadership, along the above criteria, so much the better.

\section{Making sense of uncertainty and complexity}

Before a political leader can engage in exploitation strategies to build public credibility, one must engage in individual and shared sense making. Uncertainty and complexity are key early parameters of a rapidly evolving trans-boundary challenge (and the chapters in this volume clearly illustrate how leaders around the world have grappled with these parameters in making sense of the escalating financial crisis). Crises are characterised by communications overload and by information shortage. In spite of vast investments in information-gathering agencies, intelligence analysts and a close reading of the daily news, public leaders appear genuinely taken by surprise over and over again.

As the leader of the union, you should be aware of how information is filtered and summarised before it reaches your desk. You should probe behind the seductive phrases in texts and the compelling charts in briefings. Examine how the information given to you is being framed. Time spent on a critical dialogue 
over how to diagnose the rapidly evolving situation is an investment in your remaining years as a leader in good public standing.

The institutional features around you matter for how you can deal with crises. As EU President, you are clearly not a free agent but an institutionally embedded policy shaper. Your leadership must be connected not only with proactive crisis responses, but with strategic questions of institutional design. The implementation of your national decisions is in the hands of the professionals. Coordination in crises across professional boundaries has proven to be at least as difficult as cooperation across geographical borders. The mandarins of the union's sprawling bureaucracies can hold the presidency hostage to their preferred line of action or inaction.

Crises can drive you out of control and literally out of office. Beware not to lose control of your own team. Stay proactive with your organisation and with the media. This is not the time to hide; rather, you must remain visibly on top of the dramatic situation. Do not allow yourself to be driven by events. Seize the formative moment to shape the course of events. Relate the crisis to the fundamentals of your public mission, to the storyline of your presidency.

Crises cast long shadows. Prepare yourself and your staff for dealing with cascading effects over the long haul. Monitor from the beginning the second-order consequences, which will come back to haunt you if you remain unprepared. Check how the crisis, and your handling of it, is reflected through the media. The press mirrors your actions and the appearances of action or inaction. Fluid images of success or fiasco are framed through media reports of what you seemingly did and did not do in the crisis. Is your preferred narrative the dominant one for the public meaning-making process?

Public officials often regard the media as an adversary in crises. Much of the attention of your staff is devoted to how to meet the demands of journalists. You get instant reports from your associates about how the coping effort plays out in the media. Bad reviews invite commentary within your inner circle about unfair treatment and poor journalistic styles. The crisis scenario can turn into a script of them against us. A comforting myth is created that 'we are the victims of circumstances, who are trying our best to handle a grave situation'.

Crises are not only threatening challenges to be coped with. Exploitation processes can be identified and explored, as covered in this book. Crises and their aftermaths also offer space for changes of policy, procedures and institutional designs. A period of serious inquiry, evaluation and recommendations that are based on this analysis is needed between crisis and public reform. Leadership in crisis should include a personal and organisational capacity for engaging in meaningful accountability proceedings and evaluation processes. 
Leadership in crises will sometimes invite the taking of draconian measures. Forging effective and visible action might take precedence over other equally vital considerations. Quick, forceful and possibly effective intervention in a crisis, however, might come at the price of eroding the legitimacy of democratic governance and the rule of law. At what cost to democracy, civil liberties, freedom of the press and public stature at home and abroad will your strong crisis leadership image be earned? What kind of value base do you want to embody as president, and-when push comes to shove in a crisis - do you propose the union makes trade-offs between effective and appropriate governance?

In the heat of the dramatic moments of urgency and immediacy, strategic considerations must be part of decision making. When the ordinary grind of political life again takes hold after the urgent phase has passed, draconian crisis measures will, however, appear in another light. How then to account for the choices made in the heat of the moment?

\section{Accepting the heat at the top}

The craft of governing a multinational union requires a judgment call between rash moves in the heat of crisis and sliding into the avoidance of responsibility. By emphasising certain procedural priorities, arrangements or regulations, attention can be shifted away from the substantive controversy at hand. Delays can be created through exercises in consensus building or legal requirements of unanimity. You should distinguish between a calculated postponement and a drift into avoidance by fear of taking responsibility for the whole.

The danger of entrapment at the top, rather than of splendid isolation, seems to characterise crisis decision making by European public leaders. You might find yourself highly vulnerable to the restrictions of the normative and regulatory frameworks and procedures that the professionals claim have bearings on the crisis at hand. Political leadership, however, requires sensitivity to the more ambiguous symbolic and politically charged elements of a crisis. These dimensions are rarely on the horizons of the sectoral specialists or operational professionals that might do much of the advice giving in an acute crisis. The presidency should therefore enforce a holistic view of the requirements for crisis leadership, in contrast with national concerns or sector-based perspectives grounded in distinct professions. It is best to build such a shared paradigm for trans-boundary coordination in advance of the next major crisis.

When matters go wrong, it is comforting to be able to point the finger at somebody or something else. It is tempting in the aftershock of a crisis to engage in blame shifting. One can claim that the media created a hostile event or inflamed a difficult situation in the union into a crisis. One might rationalise that with a more responsible media role, the crisis would not have erupted at all or our 
ability to manage the situation would have been much better. Crisis research shows time again, however, that it is counterproductive to blame the media for your possible shortcomings or for inflaming a situation or affecting the outcome of a crisis. You can meet the media only through a proactive posture. You cannot hope to silence journalists or crush the impact of the rapid flow of news images on the public.

If you cannot blame the media, why not point the finger inside the less than perfect construct that you have been obligated to lead? Finding scapegoats lower down the hierarchy or across the institutional or partisan divide would seem a prudent post-crisis strategy for a political leader. History is filled with examples of how mid-level officials face charges linked to crises, while the top leadership escapes from any public accountability claims. Not only is such a blame-management strategy normatively problematic, it will turn the bureaucracy against you, making it fearful of being frank when the next crisis comes along. Avoiding responsibility is short sighted. Leaders and their organisations alike thus forgo the opportunity for self-evaluation, learning and institutional reform that crises create. Teflon leadership comes at a price.

\section{Practice makes perfect}

A leader's success in a crisis rests heavily on the ability under uncertainty and time pressure to make informed choices among competing priorities. In part, this skill can be developed through experience. Seasoned officials thrive in the hectic pace of deliberations and decisions. Many tend to develop astute self-confidence in their abilities to handle high-pressure situations. The French Presidency of 2008 excelled in this skill, while the subsequent Czech Presidency paled in comparison.

The distinctive feature of national and multinational crisis decision making, however, is the onslaught of qualitatively new challenges. There are limits to the ability of political leaders to prepare for crisis coping through on-the-job experiences. You also need systematic training through scenario-based simulations to instil a sense of the unique features of crisis decision making compared with other and more frequently experienced types of policymaking situations. It is better to discover your shortcomings coping with a crisis in discrete training settings than expose them live in the media limelight.

Giving strong verbal commitment to an improved crisis-management capacity in the immediate aftermath of tragic events, such as $9 / 11,11 / 3$ or $7 / 7$, is commonplace among leaders. How many of them, however, really follow it up? The responsible public leader commits to the task of continuous capacity enhancement long after such dramatic events. Without a leadership commitment, the work towards improving the organisational capacity for low-probability but 
high-consequence events will soon slide into a low-prestige ritual without adequate staff motivation.

\section{Beyond the thrill ride}

Crisis management is a highwire-balancing act without a safety net; one wrong step and your political life could be over. Successful tiptoeing along the suspended wire might just buy you the thrill of strong public endorsement and the envy of your peers. From a democratic governance perspective, two competing dimensions must be balanced in order to enjoy the fruits of the thrill. One element of good governance is the capacity to deal effectively with crises affecting the security of societies and the safety of people. Another necessary element is the ability to strengthen the legitimacy of democratic governance through crisis-management actions within the realm of publicly accepted laws, norms and practices. Consequential actions based on urgency and immediacy must pass the scrutiny of post-crisis investigations and the ensuing accountability debates. In high-stakes situations, your leadership integrity is being put to the test - and in full public view

Crisis management also stands between stability and change. Many of the operational concerns of crisis performers are focused on dealing with traumatic events in terms of threats to political stability, public order or economic disaster. The slide is not long in crises from defending stability to becoming locked into a posture of rigidity. The imminent threat of fundamental change is then met by avoidance or by draconian measures. This fixation on ensuring stability is merely one side of the calculus of high-performance crisis management.

Leader rigidity in the face of political or financial challenges can be counterproductive to system-level transformations benefiting society and citizens. One question is often asked ex post facto by informed observers, such as scholars or journalists: a crisis for whom? As the responsible leader of the union, you should also raise this fundamental and thorny issue, while in the midst of crisis coping. What are the stakes and who are the stakeholders of this unfolding event? Where do I, as the temporary caretaker of the union of 27 democratic societies, fit into this unfolding script of turmoil between stability and change? Taking the time for some strategic reflection while in the eye of the storm is a good investment in a political future after the crisis has passed.

Crisis leadership presumes the skill to balance often overwhelming information and expert recommendations with other equally important perspectives. Sensitivity to the wider political and indeed international landscape within and beyond the union is an important quality. A robust normative compass is a source of inner strength. Political leadership often means the ability to grasp and connect with the fleeting public view of what constitutes a reasonable course 
of action in a given high-stakes situation. Crises offer windows of opportunity to move a nation or a union and to be able to take credit for having done so. 